\title{
APRENDIZAJE DIALÓGICO Y APROPIACIÓN DEL PATRIMONIO CULTURAL: Una educación patrimonial sostenida en hombros de gigantes
}

Zaida García Valecillo ${ }^{(*)}$

En la actualidad el patrimonio cultural es centro de discusión en la sociedad, pues está presente no solamente como símbolo de una nación o hechos históricos, sino como una parte activa de la vida cotidiana. Por ello ocupa un espacio en el diseño de políticas culturales, sociales y económicas, así como en el que hacer de los ciudadanos. En las últimas décadas los acelerados cambios de la sociedad moderna han transformado la mirada frente a los bienes patrimoniales, lo cual genera nuevas conexiones con el pasado que ameritan redefinir sus significados y establecer mecanismos para su apropiación. De esta manera, se facilita el fortalecimiento de las identidades, incentiva las oportunidades de desarrollo y se fortalece el sentido de pertenencia; pero paralelamente se incrementan los riesgos frente al cambio climático, los conflictos políticos o los intereses económicos. Esto tiene como consecuencia la redimensión del concepto de patrimonio, el incremento de tipologías, la formulación de nuevos criterios de valoración y la participación activa de la ciudadanía.

Todo ello abre la puerta para la creación de enfoques que orienten el diseño de planes y programas de gestión del patrimonio que respondan a los conflictos políticos, desastres naturales o problemáticas sociales que se encuentren en los alrededores de los bienes patrimoniales. En tal sentido, la participación de las comunidades en la gestión de los patrimonios ha sido un elemento reciente que permite un mayor compromiso y apoyo en las acciones a realizar (UNESCO, 2014).

En este contexto la Educación Patrimonial (EP) se viene consolidando como un área académica-operativa dentro de la gestión patrimonial, pues es necesaria la participación de los diversos actores sociales en la conservación del patrimonio y su apropiación por parte de la ciudadanía. De esta forma, disminuyen los niveles de control y se establecen mecanismos de desarrollo local sostenible alrededor del patrimonio. En tal sentido, este artículo presenta una aproximación a la Educación Patrimonial como herramienta de gestión fundamentada en enfoques teóricos que propicien el diálogo, la apropiación social del patrimonio y su posterior

\footnotetext{
${ }^{(*)}$ Doutora em Educación Artística pela Universidad de Sevilla. Professora da Universidad Pedagógica Experimental Libertador - Instituto Pedagógico de Caracas, Venezuela. E-mail: zaidagarcia@gmail.com.
} 
empoderamiento. Para ello se propone la construcción de un puente reflexivo entre las ideas que enmarcan la EP como área de estudio y el Aprendizaje Dialógico basado en las ideas de Pablo Freire, Jürgen Habermas y Ramón Flecha. Cuyos conocimientos serán (parafraseando a Isaac Newton) los hombros de gigantes que nos permitirán ver más lejos en el camino de la EP. La metodología consistió en la realización de un análisis documental de los autores seleccionados, para luego triangular los puntos de vista a través de las categorías de análisis trabajadas. Los resultados permitirán visualizar las ideas base para la formulación de enfoques pedagógicos diseñados para la Educación Patrimonial.

\section{EL PATRIMONIO CULTURAL EN LA SOCIEDAD MODERNA: DESAFÍOS EN EL SIGLO XXI}

El término PC ha sufrido grandes transformaciones, desde el siglo XIX cuando algunos objetos y edificaciones tenían un valor conmemorativo, eran una fuente de información y un símbolo de la conformación de las repúblicas; por ello las acciones se centraban en la conservación del bien. Después de la Segunda Guerra Mundial surgen otras consideraciones que son plasmadas una serie de convenciones, emitidas por la Unesco. En las cuales los países se comprometen a proteger el PC en todo el mundo; en conjunto con el marco legal local, se unifican criterios de valoración y se establecen mecanismos de protección. Entre estos instrumentos destaca la Convención para la Protección del Patrimonio Mundial, Cultural y Natural (UNESCO, 1972), la cual señala que el PC estará conformado por monumentos, conjuntos y lugares. Igualmente establece los criterios de valoración para la declaración de patrimonio mundial.

Luego surgieron categorías de patrimonio que representan las relaciones, en muchos casos ancestrales, entre los pueblos y su ambiente natural, como son los Paisajes Culturales e Itinerarios Culturales. Finalmente, se aprueba la Convención para la Salvaguardia del Patrimonio Cultural Intangibles (UNESCO, 2003) y luego la Convención sobre la Protección y Promoción de la Diversidad de las Expresiones Culturales (UNESCO, 2005), en estas se reconoce el valor de los patrimonios inmateriales, el rol protagónico de las comunidades y los derechos de autor a los exponentes de las manifestaciones. Ambas convenciones representan un paso muy importante en la defensa de las expresiones culturales sustentadas en los conocimientos y tradiciones de las comunidades. Este reconocimiento adquiere gran valor en Latinoamérica, donde se han dado largas luchas por los derechos de los pueblos indígenas y el reconocimiento de sus culturas por parte de los Estados. 
Paralelamente, existe un gran interés, por otra parte de los investigadores, de delimitar el concepto de PC, esto se puede observar en las múltiples concepciones que se recopilan constantemente. Entre las cuales destacan las de Moreno (s/d), quien establece que el patrimonio cultural puede ser visto como expresión de matrices culturales en las que los individuos y los colectivos se reconocen y se reconstruyen a sí mismos; también como espacios para la recuperación de la memoria, construcción de nuevas significaciones y realización de acciones para su porvenir. En este mismo orden de ideas, Querejazu (2013) señala que "El patrimonio no es una sucesión de objetos o elementos tangibles e intangibles, el patrimonio es "un lugar", "un territorio común" en el que se asienta e identifica una comunidad... Si la comunidad no lo usa, si no está vivo, si no se inserta en su día a día, no le pertenece, y entonces, estará condenado a la manipulación, el falseamiento, y, a la larga a la desaparición" (p. 22).

En cambio, Querol (2010) define al PC como una herencia "que hemos decidido que merece la pena proteger como parte de nuestra señas de identidad social e histórica” (p.10). Sin embargo, dicha herencia se asumen como propia dependiendo del acceso que las personas tengan a la educación y su relevancia dentro de la escala de valores de la cultura a la cual pertenece (BONFIL, 1991; GARCÍA CANCLINI, 1999). En estas definiciones se puede observar que el PC se asume como un elemento vivo dentro de la dinámica social y en permanente reafirmación en medio de la vida cotidiana. Siendo las personas y su forma de ver los bienes las que determinan su valor como PC, así como su permanencia en el tiempo.

Como se puede observar el término PC ha recorrido un largo camino donde se han transformado sus implicaciones sociales y políticas. Por lo cual se puede establecer que el patrimonio cultural es un constructo social que representa los valores culturales de una sociedad y un elemento definitorio de sus identidades. En tal sentido, es recurrente observar cómo este concepto permanece en constante construcción, pues aglutina la complejidad de la creación humana y sus significaciones en cada época. Por ello la importancia de formar una ciudadanía crítica y responsable de su patrimonio cultural, lo cual contribuirá a elevar la autoestima, así como al desarrollo sostenible de la sociedad.

En medio de esta delimitación, cabe preguntarse ¿ para quién representa un símbolo estos patrimonios?, ¿quién se reconoce en ellos?, ¿en qué radica la declaratoria de ciertos bienes?, ¿hasta qué punto el patrimonio representa la identidad y los valores de la sociedad actualmente?. Estas preguntas están envueltas en paradojas vinculadas a la relación que pueda tener los bienes patrimoniales con la sociedad. La cual se caracteriza por una gran expansión del conocimiento y 
profundas transformaciones en casi todos los ámbitos del quehacer humano. Tal como lo señala García Canclini (1999), esto implica abordar problemáticas desde:

- Patrimonio cultural y desigualdad social,

- Los usos del patrimonio,

- El propósito de la preservación,

- El patrimonio en la época de la industria cultural,

- Los criterios estéticos y filosóficos.

Estos planteamientos conllevan a repensar en el patrimonio cultural (PC) de tal manera que su gestión aborde áreas importantes como: Desarrollo Sostenible, Cambio climático, turismo, mercantilización, derechos humanos, comunicación de masas, educación, entre otros. Así como un cambio de enfoque en la gestión del patrimonio, donde el centro de interés sea la calidad de vida de las comunidades y su participación activa en el proceso de gestión. Esto permitirá validar las acciones planificadas y hacerlas sostenibles en el tiempo, pues las comunidades serán parte del proceso de gestión y en la toma de decisiones. Para ello se requiere de la construcción de metodologías que orienten la participación como mecanismo de validación de las propuestas, auspiciar dinámicas económicas sostenibles y fomentar el empoderamiento de los bienes patrimoniales (Caraballo, 2008).

\section{EDUCACIÓN PATRIMONIAL UN ESPACIOS DE EXPLORACIÓN E INVESTIGACIÓN}

En el siglo XX, la mayoría de las actividades educativas vinculadas al PC estaban, principalmente, en espacios escolares, museos o guías turísticas; dentro de la gestión patrimonial los procesos educativos se centraban en la formación técnica para la conservación. A finales del siglo XX y principios del siglo XXI, como lo señalamos anteriormente, se observan transformaciones importantes en la concepción de patrimonio, lo cual influenció en la manera de gestionar y la manera ver los procesos educativos que rodean al PC. Este viraje logró expandir la acción educativa hacia la búsqueda de didácticas particulares y establecer objetivos más allá de los procesos cognoscitivos. La educación se adentró en procesos de participación, integración social, desarrollo social, entre otros.

A esto se añade el interés de la sociedad contemporánea por legitimar el sentido de lo público y establecer conexiones con las identidades individuales y colectivas a través de la organización social y la participación real de los ciudadanos en la protección de sus patrimonios. En tal sentido, se observa el abordaje de la formación ciudadana como parte de una política social, 
económica y cultural con miras al fortalecimiento del tejido social y al desarrollo de la sociedad civil en la construcción y apropiación del espacio público (YORY, 2007). Estas ideas se ven reflejadas en acuerdos internacionales como los Objetivos de Desarrollo Sostenible (2015-2030), aprobados por todos los países miembros de la ONU (2015). Específicamente el Obj.11, donde señala: Lograr que las ciudades y los asentamientos humanos sean inclusivos, seguros, resilientes y sostenibles. Una de sus metas es: Redoblar los esfuerzos para proteger y salvaguardar el patrimonio cultural y natural del mundo.

En este contexto, la EP adquiere otros intereses dentro de la gestión pública y los investigadores y educadores exploran múltiples escenarios. Cuyo punto de partida es la percepción que las personas tienen de su entorno cultural, más allá de reafirmar el valor del bien y su posible conservación (FONTAL, 2003). En este orden de ideas, autores como Calaf (2003), Darras (2008) y Rickenmann (2008) entre otros, han señalado la necesidad de construir nuevos enfoques que permitan a la educación actuar como mediadora entre las personas y los bienes patrimoniales, a través de facilitar el acceso a los mismos y la construcción de nuevos significados que permitan su vigencia dentro de la trama social.

En Latinoamérica por ejemplo, se ha buscado redimensionar la definición de EP y su ámbito de acción, colocándola como parte del desarrollo humano. Donde las experiencias significativas frente al bien patrimonial permitan la adquisición de conocimientos críticos y emociones generadoras de identidad y reafirmación de la autoestima. Para Horta, Grunberg y Monteiro (1999) la EP es:

(...) un instrumento de "alfabetización cultural" que posibilita al individuo hacer una lectura del mundo que le rodea, elevando la comprensión del universo sociocultural y la trayectoria histórico-temporal en la que esta insertado. Este proceso conduce a una mayor auto-estima de los individuos y comunidades y la valoración de la cultura brasilera, comprendida como múltiple y plural... El conocimiento crítico y la apropiación consciente de las comunidades de su patrimonio son factores indispensables en el proceso de preservación sustentable de sus bienes, así como el fortalecimiento de los sentimientos de identidad y ciudadanía. (p. 6).

Por otra parte, Cruz (s/f) habla de una "educación social para la conservación”, donde la EP trasciende las aulas y los círculos de especialistas, favoreciendo la reflexión en torno al ser y al estar en el seno de cada grupo humano. De igual modo, Santacana (2015) plantea ideas que se complementan con la anterior, al señalar que el PC se conserva mientras una sociedad vea a los bienes patrimoniales como parte de su contemporaneidad, de acuerdo a determinados intereses ideológicos y políticos. Esto coloca al PC como un importante elemento educativo por su valor 
identitario, su capacidad de generar representatividad y la conexión afectiva con los recuerdos y sentimientos de las personas.

Todos estos planteamientos nos hablan del desarrollo de la EP, como un área de estudio que se abre a muchos ámbitos de la sociedad contemporánea y a las posibilidades que tiene de incidir en un cambio de visión del entorno social. Pero también incidir en la defensa de los derechos civiles implícitos en la conservación y acceso de un PC, los niveles de compromiso de la ciudadanía y el sentido de pertenencia en lo individual y lo colectivo. En tal sentido, García (2015) señala que la EP tiene el desafío de formar a una ciudadanía activa y crítica que sea parte del PC, forme parte de la gestión del PC y tome parte en las decisiones y en la defensa de sus derechos. Por lo tanto, la EP estará caracterizada por la creación de enfoques y estrategias didácticas dirigidas a dinamizar la relación entre el sujeto, la resignificación de los bienes patrimoniales y su uso en la dinámica social.

Tarea nada fácil si se toma en cuenta el contexto político, social y cultural de las sociedades actuales. Sin embargo, este análisis muestra la necesidad de aproximar los valores patrimoniales a los ciudadanos y que estos formen parte sus vidas cotidianas. Para ello se requiere generar procesos educativos que fomenten la participación ciudadana y el diálogo en los diversos ámbitos de la gestión educativa y patrimonial. En tal sentido, la Educación Patrimonial (EP) como herramienta de gestión es un mecanismo que propicia la conformación de un sistema de valores entorno a los bienes patrimoniales, más allá de lo establecido por los especialistas o las leyes. Para abordar estos procesos educativos se requiere sistematizar enfoques teóricos y acciones que se materialicen en la creación de modelos educativos.

\section{EP Y APRENDIZAJE DIALÓGICO, SOSTENIDOS SOBRE HOMBROS DE GIGANTES}

De lo analizado anteriormente se desprende la inquietud de estudiar el diálogo como el principal factor para consolidar la gestión participativa del PC. Por ello la necesidad de indagar sobre los procesos de aprendizaje entorno al patrimonio desde el diálogo. Para lo cual se partió del análisis de las ideas de Freire (1970 y 1979), Habermas (2002 y 1984) y Flecha (1999). Quienes nos proporcionan las bases teóricas de un Aprendizaje Dialógico dentro de la EP, que permite la construcción de un aprendizaje a través del constante intercambio de conocimientos del PC (técnico o no), habilidades, experiencias y retroalimentación. Esto como producto de la comunicación, respeto y reflexión entre los actores, análisis del entorno, el desarrollo de competencias y el trabajo mutuo. 
Según Flecha (1999) el aprendizaje dialógico es un enfoque educativo-comunicativo, en el cual existe un permanente intercambio de saberes entre los actores para la transformación del contexto y el respeto a las diferencias. Este enfoque concibe el proceso educativo dentro de una acción comunicativa centrada en la participación del educando y su percepción de la realidad; logrando una constante retroalimentación y nutriéndose del conocimiento técnico científico. Por otra parte, Aubert y otros (2006) definen este enfoque como “... aquel aprendizaje que resulta del diálogo igualitario, esto es, del diálogo entre iguales basado en pretensiones de validez" (p. 124). Ambas opiniones definen el aprendizaje dialógico como un proceso que se basa en relaciones de igualdad y donde los conocimientos de los participantes se validan frente al proceso comunicativo.

De esta manera, el educando tiene un rol activo en el proceso educativo y los resultados pueden incidir en la percepción de la realidad y posteriormente transformarla, según los intereses y necesidades de los educandos. Por ello, es factible concebir programas de EP que hagan énfasis en la acción cultural y la participación de los ciudadanos con miras a una gestión integral del patrimonio.

Por su parte, Freire (1979) indica que los procesos de aprendizaje deben apoyarse en el intercambio de percepciones, conocimientos y necesidades humanas, por medio del diálogo. Definido a éste como “...una relación horizontal que nace del conocimiento crítico de una problemática” (p. 11). El autor establece el diálogo a partir del reconocimiento del otro (el amor), el respeto sin importar su condición (la humildad), el poder de hacer, crear y transformar (la fe), un clima que promueva el diálogo en forma horizontal y armónica (la confianza) y el movimiento de las personas en permanente búsqueda (la esperanza); para el logro de la inclusión social.

Cada uno de los elementos que conducen al diálogo, tienen el objetivo de generar una pedagogía enraizada en la vida, la cultura y el tiempo-espacio de los educandos (FREIRE, 1970). Por lo tanto, el diálogo no se decreta, surge a partir del análisis crítico de una temática, donde cada participante aporta y se retroalimenta con la visión de los demás. Cuando estas ideas son llevadas al PC se observa cómo este se puede insertarse en programas educativos desde la formación ciudadana. Por otra parte, cada persona debe definir su rol y su responsabilidad individual con relación al PC; como señala Freire (1970) el sujeto "no es cosa que se rescata, sino sujeto que se debe auto-configurar responsablemente" (p. 9).

Dentro de este contexto, la Teoría de la Acción Comunicativa de Habermas (1992 y 2002) nos permite profundizar en el fenómeno comunicativo dentro del Aprendizaje Dialógico. El autor muestra cómo la sociedad está estructurada por un sistema de relaciones que se expresa a través de 
acciones. Para ello analiza tres modelos de acción social que regulan la actuación de los individuos en una sociedad y luego presenta los fundamentos de Acción Comunicativa.

El primero, es el Modelo de Acción Estratégico o Teleológico, en el cual "El actor realiza sus fines o hace que se produzca el estado deseado eligiendo en una situación dada medios que ofrezcan perspectivas de éxito y aplicándolos de forma adecuada”. (HABERMAS, 1984, p. 482483). Este tipo de acciones están dirigidas al éxito y como tal, el actor planifica sus estrategias. El actor selecciona y calcula los medios en función de la utilidad. Frente a otros actores con igual objetivo se producen interacciones frecuentes orientadas a la complementariedad y se equilibran los intereses. En este modelo las acciones no buscan el consenso y tienden a ser de carácter individualista. Dentro de la EP este tipo acción se puede observar en las iniciativas de los líderes locales, pero debe complementarse con otras acciones que de carácter grupal, pues, por si sola podrían dificultar el diálogo y puede dar como resultado la ejecución de actividades aisladas, sin consenso de los demás actores que intervienen en la gestión.

El segundo, es el Modelo de Acción Normativa, el cual se refiere a las acciones que responden a los valores comunes y unas pautas de comportamiento generalizadas. Este tipo de acción “... responde a un orden social que es entendido como sistema de normas reconocidas o de instituciones vigentes" (HABERMAS, 1984, p. 487). Donde las normas delimitan las acciones que cada miembro de un grupo social debe realizar en determinadas situaciones. Por ello el lenguaje se concibe como "... un medio que transmite valores culturales y que es portador de un consenso que simplemente queda ratificado con cada nuevo acto de entendimiento" (HABERMAS, 2002, p. 137). Estas ideas orientan a la EP hacia acciones dirigidas al cumplimiento de normas que favorezcan la conservación, el adecuado uso de los bienes patrimoniales y cumplimiento de las leyes que regulan su protección.

El tercero, es el Modelo de Acción Dramatúrgica relacionado con la proyección que cada individuo hace de su imagen. Esta revela su subjetividad de forma más o menos calculada, dependiendo del tipo de imagen que quiere dar de sí mismo. Habermas (2002) señala que el lenguaje en este modelo es un medio por el cual el individuo expresa su autoescenificación o autorepresentación de sus vivencias de acuerdo a la imagen que quiere proyectar. Estas ideas conducen a indagar sobre la importancia de trabajar la EP desde un enfoque de cultura ciudadana. En la cual se aborde la autorepresentación de los ciudadanos y sus vinculaciones con los patrimonios culturales que los identifica y los conecta con su historia. 
Finalmente, Habermas propone el Modelo de Acción Comunicativa fundamentado en acciones basadas en la intención simbólica. Donde el individuo construye redes de valores sociales a través del lenguaje y el entendimiento entre los sujetos. Aquí el lenguaje interviene como mediador de la relación entre el actor y mundo, como una manera de estructurar las redes de valores sociales. En este contexto se debe tomar en cuenta el rol social y la identidad de las personas. Habermas señala en su teoría que el leguaje es

(...) un medio de entendimiento sin más abreviaturas, en que hablantes y oyentes se refieren, desde el horizonte preinterpretado que su mundo de la vida representa, simultáneamente a algo en el mundo objetivo, en el mundo social y en el mundo subjetivo, para negociar definiciones de la situación que puedan ser compartidas por todos. (2002, p. 137).

Al estudiar estas ideas en el ámbito patrimonial, se devela la importancia del PC en ese proceso de construcción de los valores sociales y entendimiento de las personas en la vida cotidiana y en los entornos sociales. Cuando contextualizamos estas acciones dentro del ámbito educativo, espacialmente en la EP, podemos ver cómo la educación propicia la articulación consensuada de normativas y procesos participativos que dibujan la manera de interactuar los ciudadanos con el PC dentro del medio social. Un aprendizaje dialógico dentro de la EP, basado en acciones comunicativas puede propiciar o expandir las conexiones simbólicas y afectivas por el PC. Así como redimensionar el rol PC en una sociedad y en la manera como las personas se identifican, apropian y dialogan con los bienes patrimoniales.

\section{ESPACIOS OPERATIVOS PARA EL APRENDIZAJE DIALÓGICO}

Por su parte, Flecha y Puigvert (s/d), así como Elboj y otros (2006) proponen que los espacios educativos (como lo son los PC) sean vistos como Comunidades de Aprendizaje; cuyo propósito es generar procesos de aprendizaje a partir del diálogo igualitario y dirigido a la inclusión de los educandos en la sociedad de la información. Para ello, se fundamentan en un aprendizaje guiado por el diálogo y donde cada participante aporta elementos significativo para lograr la transformación del contexto social y cultural. Las comunidades de aprendizaje incorporan a los diversos actores sociales (educando, docente, familiares y otros actores de la comunidad) en la discusión y en la toma de decisiones de las propuestas educativas.

Dichas comunidades brindan la posibilidad de incidir en los valores sociales y en la red de conexiones que establece la sociedad, en términos de igualdad étnica, social, cultural o económica. Dentro de este contexto valores como la cooperación y la solidaridad se expresan de forma positiva, a través de acciones reguladas por normas consensuadas. Así desde esta perspectiva el 
conocimiento es el producto de la interacción entre de los individuos y grupos, sus experiencias, la información del patrimonio y su representación en el imaginario de los educando.

Cuando llevamos estas ideas al ámbito patrimonial vemos cómo el rol de la EP se extiende a diversos espacios y se perfila como una herramienta de gestión social del patrimonio. Es por ello que, los procesos de participación son muy importantes para lograr la conformación de una red de valores sociales entorno a los patrimonios y la incorporación del PC al quehacer cotidiano de los ciudadanos. En el momento que una comunidad de aprendizaje decida, por consenso, que los PC son sus referentes culturales y se organiza para su protección, indica un alto nivel de apropiación y altas posibilidades que su protección se extienda. Pero para lograrlo, es necesario que las personas e instituciones que conviven a diario con los bienes patrimoniales los perciban como suyo.

\section{APRENDIZAJE DIALÓGICO EN LA EP DESDE LA INTEGRACIÓN DE IDEAS}

A continuación se concibe la integración de las ideas previamente analizadas de Freire, Habermas y Flecha en función de la EP a través de los cuatro pilares pedagógicos propuestos por la Comisión Internacional sobre la Educación para el Siglo XXI ante la Unesco (DELORS, 1999), estos son: Aprender a conocer, Aprender hacer, Aprender a convivir, Aprender a ser. Dichos pilares se usaron en el presente artículo como categorías de análisis para establecer afinidades entre los autores estudiados y cuya se encuentran en diferentes tendencias del pensamiento. Al trasladar estas categorías al contexto patrimonial fue necesario reinterpretar su definición y delimitarlas de la siguiente manera:

Aprender a Conocer: "Combinando una cultura general suficientemente amplia con la posibilidad de profundizar los conocimientos en un pequeño número de materias. Lo que supone además: aprender a aprender para poder aprovechar las posibilidades que ofrece la educación a lo largo de la vida" (DELORS, 1999, p. 35). Identificar los fundamentos teóricos y estrategias pedagógicas concebidas para la apropiación de conocimientos sobre los patrimonios culturales y los fenómenos sociales, económicos, políticos, ambientales y culturales que rodean a estos.

Aprender Hacer: "A fin de adquirir no sólo una calificación profesional sino, más generalmente, una competencia que capacite al individuo para hacer frente a gran número de situaciones y a trabajar en equipo. Pero, también, aprender a hacer en el marco de las distintas experiencias sociales o de trabajo..." (DELORS, 1999, p. 35). Trabajar el desarrollo de competencias cognitivas o procedimentales utilizadas para la conservación, valoración o difusión de los valores del patrimonio cultural. 
Aprender a Convivir: "Juntos desarrollando la comprensión del otro y la percepción de las formas de interdependencia -realizar proyectos comunes y prepararse para tratar los conflictosrespetando los valores de pluralismo, comprensión mutua y paz" (DELORS, 1999, p. 35). Identificar las ideas o estrategias pedagógicas que propicien el trabajo en equipo para la protección del PC y fomenten el respeto mutuo ante la diversidad cultural.

Aprender a Ser: "Para que florezca mejor la propia personalidad y se esté en condiciones de obrar con creciente capacidad de autonomía, de juicio y de responsabilidad personal. Con tal fin, no menospreciar en la educación ninguna de las posibilidades de cada individuo: memoria, razonamiento, sentido estético, capacidades físicas, aptitud para comunicar...” (DELORS, 1999, p. 35). Reconocer las ideas o estrategias pedagógicas que incrementan las capacidades individuales para el análisis crítico sobre el PC y su contexto, la autoestima y la responsabilidad individualciudadana.

En tal sentido, la siguiente tabla transfiere la secuencia de ideas referidas al aprendizaje dialógico en el contexto de la EP, de acuerdo a las categorías trabajadas.

\begin{tabular}{|c|c|c|c|}
\hline Categorías & Pablo Freire & Jürgen Habermas & Ramón Flecha \\
\hline Conocer & $\begin{array}{l}\text { Desafiar al educando para } \\
\text { que despierte la curiosidad y } \\
\text { la permanente búsqueda. } \\
\text { Aprehender los contenidos } \\
\text { como objeto de } \\
\text { conocimiento. A partir de la } \\
\text { realidad del educando, sus } \\
\text { niveles de percepción y su } \\
\text { visión del mundo. }\end{array}$ & $\begin{array}{l}\text { Conocer la red de valores } \\
\text { sociales que se tejen alrededor } \\
\text { del PC. }\end{array}$ & $\begin{array}{l}\text { Intercambio de } \\
\text { conocimiento en un } \\
\text { contexto de diálogo. } \\
\text { Conjugar el aprendizaje } \\
\text { técnico-científico con las } \\
\text { experiencias y reflexiones } \\
\text { de cada individuo. }\end{array}$ \\
\hline Hacer & $\begin{array}{l}\text { Fortalecer las capacidades } \\
\text { creativas } \\
\text { Desarrollo creativo del } \\
\text { lenguaje. }\end{array}$ & $\begin{array}{l}\text { Acciones comunicativas que } \\
\text { responden a la construcción de } \\
\text { un mundo social y subjetivo. De } \\
\text { las características de esta } \\
\text { construcción dependerá la } \\
\text { manera de actuar frente al PC. }\end{array}$ & $\begin{array}{l}\text { Mejorar las habilidades } \\
\text { comunicativas como parte } \\
\text { fundamental de la } \\
\text { inteligencia cultural. }\end{array}$ \\
\hline Convivir & $\begin{array}{l}\text { Respeto a las diferencias, en } \\
\text { un contexto de igualdad y } \\
\text { armonía. }\end{array}$ & $\begin{array}{l}\text { Acciones que responden a las } \\
\text { normas logradas por consensos } \\
\text { entre los miembros de un grupo. }\end{array}$ & $\begin{array}{l}\text { La solidaridad como un } \\
\text { principio para generar la } \\
\text { convivencia multicultural. } \\
\text { Trabajar con grupos } \\
\text { interactivos, donde se } \\
\text { comparte información y } \\
\text { discute las diversas } \\
\text { posibilidades para convivir } \\
\text { con el PC. Teniendo como } \\
\text { base el diálogo igualitario. }\end{array}$ \\
\hline
\end{tabular}




\begin{tabular}{|l|l|l|l|}
\hline Ser & $\begin{array}{l}\text { Diálogo a partir del } \\
\text { reconocimiento del otro. }\end{array}$ & $\begin{array}{l}\text { El diálogo orienta la acción } \\
\text { comunicativa de los ciudadanos } \\
\text { y las autorepresentaciones hacia } \\
\text { la construcción de valores } \\
\text { patrimoniales. }\end{array}$ & $\begin{array}{l}\text { Transformar las relaciones } \\
\text { entre las personas y su } \\
\text { entorno patrimonial. }\end{array}$ \\
$\begin{array}{l}\text { Capacidad de } \\
\text { transformación de los } \\
\text { individuos }\end{array}$ & & \\
\hline
\end{tabular}

En esta tabla se puede observar cómo al colocar las ideas de cada autor en el contexto patrimonial y particularmente desde la EP se complementan. Es así como se puede establecer que desde el Aprender a Conocer el aprendizaje dialógico parte de la exploración, la aproximación a las redes de valores que rodea al bien patrimonial y el intercambio de percepciones, que se contrastan con los datos técnicos - científicos y las significaciones que estos bienes generan. El aprendizaje no se asume como un proceso para superar un déficit de información histórica o artística sobre el bien, sino como un proceso donde la comunidad de aprendizaje trabaja en función del intercambio de cocimientos y acciones que dibujan la realidad del PC y su relación con la sociedad.

Luego el Aprender Hacer se centra el desarrollo de las capacidades creativas y comunicativas de los educando y su aplicación en las diversas situaciones y conflictos que rodean la gestión del patrimonio. Para ello se debe trabajar en equipo y hacer sinergia entre los actores sociales en pro de un objetivo común. De tal manera que las acciones comunicativas estén dirigidas a la construcción de un mundo social y subjetivo. Por otra parte el Aprender a Convivir busca construir mecanismos de diálogo donde se respete la manera de pensar y/o hacer de las demás personas. Comprender que para lograr los objetivos se debe dialogar en un ambiente de igualdad e identificar los obstáculos desde el pluralismo de ideas y creencias, muchas veces en contextos dinámicos y cambiantes pero con respeto. Lo cual abre la posibilidad a plantearse la inserción del PC dentro de la vida cotidiana de diversas maneras y facilitando su acceso. El Aprender a Ser hace énfasis en el fortalecimiento del valor del individuo como parte del PC, lo cual conlleva a las personas a expresar sus percepciones y opiniones personales sobre el PC de forma argumentada. El diálogo y el patrimonio cultural como factores para la reafirmación de las identidades culturales.

Para finalizar, debemos destacar la significativa importancia que tiene la EP como un proceso dialógico, donde cada uno de estos basamentos teóricos representan una pieza de un rompecabeza. Donde los educandos identifiquen, desde una visión crítica, los valores sociales y los elementos patrimoniales a defender. Al estudiar en conjunto el Aprendizaje Dialógico a través de las categorías seleccionadas se facilita el establecer los elementos de análisis y argumentación para el desarrollo de un aprendizaje fundamentado en las capacidades creadoras del ser humano y el 
fortalecimiento del diálogo. Lo cual permite incorporar los valores simbólicos que la ciudadanía le atribuye al PC en la gestión patrimonial. Esto contribuye a que los actores sociales involucrados en el proceso de gestión se comuniquen a través de un diálogo igualitario, donde especialistas y ciudadanos construyan conocimientos para lograr el pleno acceso al patrimonio y al desarrollo sostenible de las localidades. Por lo tanto, para esta investigación se asume el Aprendizaje Dialógico como un proceso de interacción, reflexión y comunicación entre los participantes y la realidad que envuelve al PC. Donde el diálogo será una constante a lo largo del proceso de aprendizaje. De tal manera, que cada participante establezca una apropiación crítica del conocimiento patrimonial para de la vida; elabore herramientas que le permitan acceder a manera creativa al PC, proteger e interactuar con el PC; propicie la cooperación y por último adquiera un sentido de pertenencia e identidad. 


\section{REFERENCIAS}

BONFIL, G. Pensar nuestra cultural. México: Alianza. 1991

CALAF, R. Aprender arte en la ciudad: Sensibilizar hacia el respeto y la valoración del patrimonio urbano. In: Arte para todos. Miradas para enseñar y aprender el patrimonio. España: Trea. 2003

CARABALLO, C. El patrimonio cultural y los nuevos criterios de intervención. La participación de los actores sociales. Revista Palapa, México, v. 3, n. 1. p. 41-49. 2008. Disp.: 〈http://www.redalyc.org/pdf/948/94811212006.pdf〉. Consulta: 02 Julio 2010.

CRUZ, S. (s/f). La educación social para la conservación en el proceso de construcción de la corresponsabilidad sobre el patrimonio cultural. Correo del restaurador, n 6. Disp.: <http://www.conservacionyrestauracion.inah.gob.mx/html/ Publindice.html\#>. Consulta: 18 Sept. 2011.

DARRAS, B. Del patrimonio artístico a la ecología de las culturas. La cuestión de la cultura elitista en democracia. In: El acceso al patrimonio cultural. Pamplona, España: Universidad Pública de Navarra. 2008

DELORS, J. La educación encierra un tesoro. París: Unesco. 1999.

FONTAL, O. Educación Patrimonial. Teoría y Práctica en el Aula, el Museo e Internet. Asturias, España: Trea. 2003

FREIRE, P. Educación y Acción Cultural. Madrid: Zero. 1979

FREIRE, P. Pedagogía del Oprimido. 14 ed. Buenos Aires: Siglo XXI, 1970

GARCIA CANCLINI, N. Los usos sociales del Patrimonio Cultural. In: AGUILAR CRIADO, E. Cuadernos Patrimonio Etnológico. Nuevas perspectivas de estudio. España: Consejería de Cultura, Junta de Andalucía, p. 16-33. 1999.

GARCÍA, Z. La educación patrimonial. Retos y pautas para educar a la ciudadanía desde lo patrimonial en latinoamérica. Revista Cabás. España, n. 14, p. 58-73. Diciembre 2015. Disp.: <http://revista.muesca.es/ index.php/articulos14/346-la-educacion-patrimonial>. Consulta: 11 marzo 2016.

HABERMAS, J. Teoría de la acción comunicativa: Complementos y estudios previos. 3. ed. Madrid. Cátedra. 1984 Teoría de la acción comunicativa, I. Racionalidad de la acción y racionalización social. México: Taurus.

2002.

. Teoría de la acción comunicativa, II. Crítica de la razón funcionalista. Madrid: Taurus. 1992

HORTA, M., GRUNBERG, E.; MONTEIRO, A. Guía básica de educação patrimonial. Brasilia: Instituto do Patrimõnio Histórico e Artístico Nacional. 1999.

ONU. Objetivos de Desarrollo Sostenible. Nueva York: USA. 2015. Disp.: <http://www.un.org/sustainabledevelop ment/es/objetivos-de-desarrollo-sostenible/>. Consulta: 10 Marzo 2016.

QUEREJAZU, P. Apropiación social del patrimonio. In: Cuaderno Patrimonio cultural y turismo, n. 20, 2013. Disp.: <http://www.cultura.gob.mx/turismocultural/cuadernos/pdf20/articulo2.pdf〉. Consulta: 23 Marzo 2014.

MORENO, M. (s/f). Acción social para la conservación del patrimonio cultural. Correo del Restaurador. n. 6. Disp.: <http://conservacion.inah.gob.mx/publicaciones/wp-content/uploads/2015/10/Correo-Restaurador-No.-6.pdf>.

Consulta: 18 Sept. 2015.

QUEROL, M. Manual de gestión del patrimonio cultural. Madrid: Akal. 2010

RICKENMANN, R. Arte, patrimonio y experiencia estética. Hacia una reconcepción de las enseñanzas artísticas basada en el análisis de la mediación docente. In: El acceso al patrimonio cultural. Pamplona, España: Universidad Pública de Navarra. 2008.

UNESCO. Convención para la protección del patrimonio mundial, cultural y natural. 1972. Disponible: www.unesco.org/whc. Consulta: 20 Enero. 2000.

Convención para la Salvaguardia del Patrimonio Cultural Intangibles. 2003. Disp.: 〈www.unesco.org/whc>. Consulta: 20 Enero 2005.

Convención de Protección y Promoción a la Diversidad de Expresiones Culturales. 2005. Disp.: <www.unesco.org/whc>. Consulta: 15 Mayo 2007. 
UNESCO. Gestión del patrimonio mundial cultural. Manual de referencia. Francia, 2014. Disp.: <http://whc.unesco.org/document/130490>. Consulta: 7 abril 2016

YORY, C. La formación de competencias técnicas sociales. In Yory, C (Edit. Académico). Espacio público y formación de ciudadanía. Bogotá: Pontificia Universidad Javeriana. pp 135-158. 2007

\section{RESUMEN}

El presente artículo propone una aproximación a la Educación Patrimonial (EP) como herramienta de gestión del patrimonio cultural fundamentado en enfoques teóricos que propicien el diálogo, la apropiación social del patrimonio y su posterior empoderamiento. Para ello se plantea establecer una conexión entre las ideas que delimitan la EP como área de estudio y el Aprendizaje Dialógico, el cual se sustenta en las ideas de Pablo Freire, Jürgen Habermas y Ramón Flecha. En tal sentido, se realizó un análisis documental de los autores seleccionados, para luego triangular los puntos de vista en función de las categorías de análisis seleccionadas.

Palabras Clave: Educación patrimonial. Patrimonio cultural. Aprendizaje Dialógico.

\section{APRENDIZAGEM DIALÓGICA E APROPRIAÇÃO DO PATRIMÔNIO CULTURAL: UMA EDUCAÇÃO PATRIMONIAL SUSTENTADA EM OMBROS DE GIGANTES}

\section{RESUM}

Este artigo propõe uma abordagem para a Educação Patrimonial (EP) como uma ferramenta para a gestão do patrimônio cultural com base em abordagens teóricas que são orientadas pela promoção do diálogo, da apropriação social do patrimônio e do empoderamento. Para tal, propõe-se a estabelecer uma ligação entre as ideias que definem a EP como uma área de estudo e a aprendizagem dialógica, a última baseada nas ideias de Paulo Freire, Jürgen Habermas e Ramon Flecha. A este respeito, foi realizada uma análise documental dos autores selecionados, seguida de uma triangulação de seus pontos de vista em função de categorias de análise selecionadas.

Palavras-chave: Educação patrimonial. Patrimônio cultural. Aprendizagem dialógica.

\section{DIALOGIC LEARNING AND OWNERSHIP OF CULTURAL HERITAGE: A WEALTH EDUCATION ON SHOULDERS OF GIANTS SUSTAINED}

\section{ABSTRACT}

The article herein proposes an approximation to heritage education as a management tool for cultural heritage with a foundation focused on theories that stimulate dialogues, the social engagement of heritage and its subsequent empowerment. For the latter, the synchronization of the idea of heritage education as an academic area of study, and dialogic learning, as planted by the thoughts of Pablo Freire, Jürgen Habermas, and Ramón Flecha, are set forth for consideration. Pursuant to the aforementioned, a documentary analysis of the three selected authors was conducted to gather each of their thoughts and ideas, with the aim to utilize these for the categories to be analyzed.

Keywords: Heritage education. Cultural heritage. Dialogic Learning. 